\title{
DEMANDAS DOS BEBÊS: AS PERCEPÇÕES DAS PROFESSORAS SOBRE O PLANEJAMENTO NO BERÇÁRIO
}

\section{BABY DEMAND: THE TEACHER'S PERCEPTIONS ABOUT PLANNING IN THE NURSERY}

\section{Kelly de Oliveira Cardoso ${ }^{1}$ \\ Gislene Camargo ${ }^{2}$}

\begin{abstract}
RESUMO: O presente artigo teve como objetivo geral analisar as intencionalidades pedagógicas nas turmas de berçário, procurando responder o problema: Como deve acontecer o planejamento no berçário. Com isso, definiram-se como objetivos específicos: compreender a relação cuidar e educar nas turmas de berçário da Educação Infantil, relacionar o cuidar e educar ao planejamento e verificar a importância do projeto como planejamento no berçário. Para responder o problema e atingir os objetivos realizou-se uma pesquisa de campo de abordagem qualitativa. Com relação aos sujeitos da pesquisa, seis professoras da Educação Infantil foram entrevistadas. Dessas quatro já aturam nas turmas de berçário e duas estão atuando; três professoras pertencem a uma escola particular e três professoras a um Centro de Educação Infantil público, ambos localizam-se no município de Sombrio-SC. Como instrumento de coleta de dados utilizou-se entrevista semiestruturada contendo sete perguntas relacionadas ao cuidar e educar, planejamento e rotinas, os dados foram analisados à luz teórica, utilizando os seguintes autores: Brasil (2010), Barbosa e Horn (2008), Freitas (1999), Kramer (2005), entre outros. Neste estudo, foi possível perceber que as professoras apresentam entendimento sobre a importância do planejamento para o berçário, e as entrevistadas utilizam projetos como metodologia, procurando aliar o cuidar e o educar. Em determinados momentos o cuidar ainda se destacou, especialmente no que se refere ao cumprimento das rotinas.
\end{abstract}

PALAVRAS-CHAVE: Cuidar e educar. Planejamento. Rotina. Educação Infantil.

ABSTRACT: This article aimed to analyze the pedagogical intentions in the nursery classes, looking to answer the problem of how the planning in the nursery should happen. With this, the following specifics objectives were defined: to understand the relation caring and education in nursery classes of Child Education, to relate care and education to planning and verify the importance of the project as a planning in the nursery.To answer these questions

\footnotetext{
1 Acadêmica do curso de Pedagogia Licenciatura na Universidade do Extremo Sul Catarinense UNESC. oliveirakcardoso@ hotmail.com

Orientadora. Mestre em educação (UNESC). Pedagoga. Psicopedagoga Institucional em uma escola de Educação Infantil. Coordenadora PIBID Pedagogia E.I. gislene@ unesc.net

Saberes Pedagógicos, Criciúma, v. 3, n³, Edição Especial 2019.- Curso de Pedagogia - UNESC
} 
and reach the objectives, a qualitative approach field research was carried out, the subjects of the research were six teachers of the Child Education, with four of them who already worked in nursery classes and two of them are still working in this area, three teachers belong to a private school and the other three teachers to a public CEI (Child Education Center), both are localized in the city of Sombrio/SC. A semi-structured interview was used as an instrument of data collection, the interview contained seven questions related to the caring and education, planning and routines, the data were analyzed in the theoretical light, using the following authors: Brasil (2010), Barbosa and Horn (2008), Freitas (1999), Kramer (2005), among others.In this study was possible to perceive that the teachers show an understanding about the importance of planning in nursery class, and the interviewed still use planning as methodology, looking to ally the care and the education. At certain times the care still stood out, especially with regard to the routines compliance.

KEYWORDS: Care and educate. Planning. Routine. Child Education.

\section{INTRODUÇÃO}

A Educação Infantil é um campo vasto para observações e escritas a respeito das suas dinâmicas. Nesta etapa às demandas dos bebês no berçário são diferentes das crianças da pré-escola. E foi ao adentrar em uma sala de berçário para realizar o estágio não obrigatório, que a curiosidade sobre as práticas pedagógicas nesse seguimento aflorou. O interesse em pesquisar sobre este assunto, aumentava a cada dia na turma de berçário, que atende crianças de 4 meses a 1 ano e 8 meses de idade. Por meio de observações das rotinas da sala e das práticas das professoras, foram surgindo algumas dúvidas em relação à Educação Infantil, pois o que observava não condizia com o que estava estudando na Universidade.

À medida que iam surgindo as dúvidas referentes às práticas pedagógicas das professoras, comecei a comparar com os estudos realizados durante o Curso de Pedagogia, no qual aprendemos que a prática pedagógica deve ser permeada pela intencionalidade, que exige um planejamento adequado e que contemple o cuidar e o educar. Diante das inquietações, definiu-se como problema: Como deve acontecer o planejamento no berçário?

A pesquisa teve como objetivo geral: Analisar as intencionalidades pedagógicas do berçário. Denominaram-se como objetivos específicos: Compreender a relação cuidar e educar nas turmas de berçário da Educação Infantil; Relacionar o cuidar e o educar ao planejamento; e Verificar a importância do projeto como planejamento no berçário. 
Para responder ao problema da pesquisa, foram ouvidas professoras que atuam ou já atuaram no berçário, em escolas da rede municipal de Sombrio/SC. Suas percepções sobre as demandas dos bebês e suas dinâmicas de planejamento no dia a dia do berçário, foram analisadas à luz teórica.

Desta forma, este artigo está constituído por reflexões teóricas com base nos seguintes referenciais teóricos: Ariès (1981); Diretrizes Curriculares para a Educação Infantil (BRASIL, 2010); Referencial Curricular Nacional da Educação Infantil (BRASIL, 1998); Lei de Diretrizes Bases da Educação Nacional (BRASIL, 1996); Freitas (1999); Gil (1991); Oliveira (2002); Rizzini (1997); Silva (2011); Barbosa e Horn (2008); Barbosa e Horn (2001); Costa (2014); Schmitt (2013); Silva (2011); Kramer (2005).

Este artigo contém uma introdução, dois capítulos e dois subtítulos de referencial teórico, onde o primeiro capítulo apresenta o processo histórico da Educação Infantil, apresentando todo o caminho percorrido para chegar na concepção de educação infantil que temos hoje. O segundo capítulo expõe sobre a importância de trabalhar com projetos na Educação Infantil tratando-se de como deve ser organizado o planejamento e o que deve ser levado em consideração. Ainda, este capítulo possui como subtítulos: o lugar do cuidar e o educar no planejamento que abordará a relação entre essas duas palavras mostrando sua importância nas turmas de berçário e planejamento, e o último subtítulo aborda o planejamento do espaço e tempo no berçário. No trabalho contém ainda uma metodologia que apresenta a coleta de dados, análise e uma conclusão apresentando os resultados alcançados.

\section{PROCESSO HISTÓRICO DA EDUCAÇÃO INFANTIL}

Para compreender a dinâmica do berçário é necessário situar os movimentos pelos quais a Educação Infantil vem passando no decorrer dos anos. O berçário faz parte da modalidade creche e por muito tempo foi concebido como um lugar de cuidados, onde não era prioridade planejar, somente cuidar das necessidades físicas dos bebês.

Assim, cabe lembrar que a Educação Infantil passou por um longo processo histórico, desde a desvalorização da criança e da infância até chegar ao contexto em que se encontra. Na sociedade medieval, não existia sentimento de infância. Quando a criança não 
necessitava mais da mãe ou da ama e superava o período de mortalidade, ela passava a conviver no meio dos adultos, considerado um adulto em miniatura (ARIÈS, 1981).

Com o passar do tempo foram surgindo outros sentimentos de infância, como caracteriza Áries (1981, p. 158) “em que a criança por sua ingenuidade, gentileza e graça, se tornava uma fonte de distração e de relaxamento para o adulto, um sentimento que poderíamos chamar de paparicação". Neste caso, as crianças já não conviviam mais no meio dos adultos, pois, passaram a ser fonte de divertimento.

Durante o século XVIII e parte do século XIX predominava a prática caritativa e assistencialista pelas crianças pobres, que se caracterizava no ato de recolher crianças órfãs e abandonadas. Diante disso, criam-se as "rodas de expostos" que eram instituições onde os pais abandonavam seus filhos sem identificá-los (RIZZINI, 1997). Embora as rodas de expostos tenham sido criadas para diminuir com o infanticídio e o abandono das crianças nas ruas, isto continuou acontecendo e por esse motivo este modelo foi se tornando inadequado e incompatível com a mentalidade do século XIX. Então os higienistas e demais moralistas da época polemizaram contra a assistência caritativa com base em argumentos respaldados na moral e nos conhecimentos obtidos pela ciência médica, tendo como alvo a Roda de expostos (RIZZINI, 1997).

Diante desses movimentos, surge no início do século XX a filantropia, como um modelo assistencial. Baseava-se na ciência para substituir o modelo de caridade. Atribuiu-se a filantropia o dever de organizar a assistência dentro das novas exigências sociais, políticas, econômicas e morais do país (FREITAS, 1999). Logo, surgiram os "jardins-de-infância" trazidos para o Brasil sobre influência americana e europeia, tendo assim os primeiros jardins de infância criados em 1875 no Rio de Janeiro e em 1877 em São Paulo sendo de responsabilidade das entidades privadas. Apenas alguns anos depois, criaram os jardins de infância pública. Com a criação dos jardins de infância, foram surgindo diversos debates entre os políticos da época. Freitas (1999) aponta que em 1882 Rui Barbosa apresentou um projeto de reforma da instrução no país, diferenciando salas de asilo, escolas infantis e jardins de infância, pois considerava o jardim de infância a primeira etapa do ensino primário. A partir disto, começaram a surgir algumas posições históricas em relação a educação infantil 


\section{SABERES PEDAGÓGICOS}

Revista do Curso de Graduaçāo de Pedagogia - Unesc

ISSN $2526-4559$

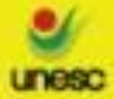

Thistivente

unese

ateintings

classificadas em assistencialismo e em uma educação compensatória aos menos favorecidos socialmente.

No decorrer dos anos foram acontecendo diversas mudanças em relação à infância e à Educação Infantil, dentre elas o Instituto de Proteção e Assistência à infância criada em 1899; em seguida, a criação do Departamento da Criança no ano de 1919 criadas pelo governo pela preocupação com a saúde pública. Além disso, surgiram diversas escolas infantis e jardins de infância, alguns destes criados por europeus para o atendimento de seus filhos (OLIVEIRA, 2002). Com a urbanização e industrialização nas grandes cidades no início do século XX, a estrutura das atividades econômicas das famílias foi modificando-se. Os homens trabalhavam na lavoura, e as mulheres passaram a trabalhar nas indústrias. Com isso, surgiu a necessidade de as mães deixarem seus filhos em algum local para que pudessem trabalhar. Desta forma, surgiram as "criadeiras", logo, chamadas de "fazedoras de anjos", pois havia alta mortalidade das crianças que elas cuidavam por conta das péssimas condições de higiene e materiais, que, segundo Oliveira (2002, p. 95), eram consequências de "problemas psicológicos advindos de inadequada separação da criança pequena de sua família."

Durante a segunda metade do século XX, com o novo sistema econômico no Brasil passam a ocorrer diversas mudanças e entre elas a mais importante, a Lei de Diretrizes e Bases da Educação Nacional aprovada em 1961(Lei 4024/61) passa a incluir os jardins de infância no seu sistema de ensino (OLIVEIRA, 2002). Além disso, foram surgindo novas discussões acerca da importância dos primeiros anos de vida no desenvolvimento da criança, possibilitando algumas mudanças no trabalho exercido nos parques infantis. Modificou-se, então, o trabalho realizado nesses locais, passando a ter caráter pedagógico voltado para atividades de maior sistematização.

Após o término do período militar, em 1985, criam-se novas políticas para as creches, incluindo-as no Plano Nacional de Desenvolvimento, elaborado em 1986. Iniciaramse novas ideias no que se referia a creche ser de importância apenas da mulher ou da família, mas de pertencer também ao governo. A partir disto, foram surgindo algumas discussões das funções da creche e da pré-escola, resultando em novas programações pedagógicas buscando acabar com as concepções assistencialistas, propondo a essas instituições uma função 
pedagógica que focasse no desenvolvimento linguístico e cognitivo das crianças (OLIVEIRA, 2002).

Através das lutas pela democratização da escola pública juntamente com os movimentos feministas e sociais de luta por creches, conquistou-se na Constituição de 1988 “o reconhecimento da educação em creches e pré-escolas como um direito da criança e um dever do Estado a ser cumprido nos sistemas de ensino." (OLIVEIRA, 2002, p. 115). Além disso, no ano 1990 é divulgado o Estatuto da Criança e do Adolescente concretizando os direitos das crianças estabelecidos pela Constituição. Essas mudanças provocaram algumas discussões em relação à Educação Infantil, influenciando na aprovação da nova LDB em 1996, que estabeleceu a Educação Infantil como etapa inicial da educação básica.

As discussões referentes à Educação Infantil resultaram em novas políticas públicas trazendo leis e documentos oficiais a respeito de sua importância e função, regulamentando seu ensino. Atualmente, existem os seguintes documentos oficiais que dizem respeito à Educação Infantil: Constituição Federal de 1988, ECA, Política Nacional de Educação Infantil, Referencial Curricular Nacional para a Educação Infantil (RCNEI), Diretrizes Curriculares Nacionais para a Educação Infantil, Parâmetros Nacionais de Qualidade para a Educação Infantil (SILVA; FRANCISCHINI, 2011). É a partir da elaboração desses documentos que percebemos uma possível preocupação com a educação das crianças pequenas, resultando em um novo conceito do que é educar nessa faixa etária, para isso o RCNEI ressalta que,

\footnotetext{
Educar significa, portanto, propiciar situações de cuidados, brincadeiras e aprendizagens orientadas de forma integrada e que possam contribuir para o desenvolvimento das capacidades infantis de relação interpessoal, de ser e estar com os outros em uma atitude básica de aceitação, respeito e confiança, e o acesso, pelas crianças, aos conhecimentos mais amplos da realidade social e cultural. (BRASIL, 1998, p. 23).
}

Além disso, a LDB torna obrigatória e gratuita a educação básica dos 4 aos 17 anos de idade, sendo a educação infantil até os 5 anos de idade (BRASIL, 1996).

Tendo em vista todo o percurso histórico da Educação Infantil, é importante refletir sobre sua função, pois, segundo Lordelo (2002, apud SILVA; FRANCISCHINI, 2011, p.18), "o papel assistencialista parece ser uma marca das instituições públicas e o papel Saberes Pedagógicos, Criciúma, v. 3, n³ 3, Edição Especial 2019.- Curso de Pedagogia - UNESC 
educacional parece estar relacionado às instituições privadas". Tendo em vista que a Educação Infantil tenha passado por diversas concepções até chegar na qual se encontra hoje, possuindo diversos documentos oficiais que regulamentam e valorizam seu ensino, o papel assistencialista parece ainda estar presente, prevalecendo ainda nas instituições públicas. (SILVA; FRANCISCHINI, 2011).

O próximo capítulo explana sobre o planejamento na Educação Infantil, para que possamos compreender se o planejamento no berçário é importante, ou basta seguir a rotina diária de cuidados.

\section{PLANEJAMENTO NA EDUCAÇÃO INFANTIL: TRABALHANDO COM PROJETOS}

O Planejamento se faz importante em qualquer situação, pois, tudo que fazemos, planejamos. Por exemplo, uma viagem no final de semana necessita de planejamento afinal, não saímos viajando sem rumo. Dessa forma, dentro do ambiente escolar não poderia ser diferente. Toda e qualquer atividade preparada para as crianças necessita planejamento, pois é através do planejamento que o professor irá conseguir elaborar suas aulas. Barbosa e Horn discorrem ainda que,

as novas características da infância e da juventude não tem sido consideradas nos modos de pensar e de realizar a educação escolar. Com isso, aponta-se para uma urgente necessidade de modificação da estruturação e organização da vida escolar, com o intuito de construir significados para as aprendizagens e para a experiência dos alunos. (BARBOSA; HORN, 2008, p. 24).

Através disso, surgem outros meios de elaborar o planejamento um deles é trabalhar com projetos. Segundo Barbosa e Horn (2008, p.31) "os projetos permitem criar, sob forma de autoria singular ou de grupo, um modo próprio para abordar ou construir uma questão e respondê-la." Trabalhar com projetos é possibilitar que a criança aprenda a pesquisar, a criar, a pensar, a exercer a crítica, a ter dúvidas e argumentar. Além disso, é importante ressaltar que o tema escolhido para construção do projeto não está determinado nem surge do professor ou livro didático, e sim do conjunto de saberes do professor e das 
crianças. Valoriza-se o conhecimento de cada criança e a forma que esse conhecimento pode ser relacionado fora e dentro da escola ou no centro de educação infantil (HERNÁNDEZ, 1998).

$\mathrm{Na}$ Educação Infantil, muitos acreditam que as crianças não possuem a necessidade de aprender pelo fato de serem pequenas, principalmente no berçário. Isto é decorrente de sua origem, que antigamente as crianças iam para as creches apenas para serem cuidadas, sem preocupação com a aprendizagem (BARBOSA; HORN, 2001). As crianças desde muito pequenas aperfeiçoam suas experiências já existentes e adquirem novas. Então, todo contato com o mundo, a criança estará desenvolvendo e construindo aprendizagens. Com essas características específicas das crianças pequenas, se faz necessário uma organização muito específica do trabalho pedagógico e do ambiente físico, essa organização pode se dar através dos projetos (BARBOSA; HORN, 2008).

Os projetos de trabalho possuem grande valor simbólico, pois, através deles é possível aproximar-se da identidade do aluno, mostrando que a função da escola ou centro de educação infantil não é apenas ensinar conteúdos e sim, fazer sempre uma relação com o que acontece fora da escola, mostrando as crianças que existe um mundo cheio de informações que constroem o meio em que vivemos (HERNÁNDEZ, 1998). Dessa forma, conseguimos fazer com que as crianças conheçam o meio em que estão inseridas e aprendam a interagir de forma crítica.

Segundo Barbosa e Horn (2008, p.74) "os projetos com bebês têm seus temas derivados basicamente da observação sistemática, da leitura que a educadora realiza do grupo e de cada criança." Assim, é importante que a professora esteja sempre atenta em como as crianças expressam seus gostos e interesses, pois é a partir dessas observações que ela irá encontrar os temas e os problemas para construção dos projetos.

Um projeto pode iniciar de qualquer manifestação curiosa de uma criança, que após as observações do professor, poderá gerar um projeto. É importante salientar ainda,

\footnotetext{
Nessa faixa etária, é fundamental considerar que as coisas importantes da vida a serem descobertas e conhecidas são a procura do olhar, o ser correspondido, o sorrir, a conversa (seja qualquer tipo de relação vocal), o tocar (contato motor), o contato físico, a retenção de um objeto (dar, oferecer), o imitar, o esconder, os jogos de linguagem, os jogos de manipulação, as músicas, as saídas para o espaço externo, as festas, a vida em grupo. As atividades de sobrevivência, como alimentar-se, banhar-
}

Saberes Pedagógicos, Criciúma, v. 3, n³, Edição Especial 2019.- Curso de Pedagogia - UNESC 
se, brincar, dormir, comunicar-se verbalmente e relacionar-se com os companheiros, também são as grandes aprendizagens desse grupo etário. (BARBOSA; HORN, 2008, p. 80).

Quando se pensa na construção de projetos, é necessário não considerarmos que o mesmo se refere a um "método", pois um método é algo que já está determinado, preestabelecido ou um conjunto de regras a serem cumpridas (HERNÁNDEZ,1998). Dessa forma, o projeto é totalmente flexível que envolve e considera o conhecimento de todos os envolvidos, está em constante construção.

O ponto inicial para elaboração de um projeto será sempre a observação e o diálogo, levando em consideração o conhecimento que as crianças já possuem. A duração de um projeto pode ser de um dia ou de uma semana, o que vai influenciar nesse tempo é o envolvimento das crianças. Por esse motivo trabalhar com projetos se torna flexível, pois durante sua execução as crianças e os educadores vão decidindo qual o melhor caminho e propondo diferentes atividades de acordo com o tema. A organização do trabalho pedagógico por meio de projetos considera as crianças como coautoras do seu processo de aprendizagem, fazendo com que participem ativamente daquilo que está sendo ensinado, transformando todos envolvidos em 'protagonistas'(BARBOSA; HORN, 2008).

O planejamento por meio de projetos é uma forma de motivar as crianças pelo fato delas mesmas estarem envolvidas no processo de aprendizagem. Bem como:

\footnotetext{
Os projetos de trabalho constituem um planejamento de ensino e aprendizagem vinculado a uma concepção da escolaridade em que se dá importância não só à aquisição de estratégias cognitivas de ordem superior, mas também ao papel do estudante como responsável por sua própria aprendizagem. (HERNÁNDEZ, 1998, p. 89).
}

A prática pedagógica por meio dos projetos possibilita aos professores que inovem seus planejamentos e que evitem trabalhar de forma fragmentada sem atender as necessidades das crianças. Desse modo, a criança consegue participar de toda a construção e elaboração dos conteúdos a serem ensinados, podendo expressar seus gostos e interesses conseguindo através disso estabelecer relações com a realidade. 


\section{SABERES PEDAGÓGICOS}

Revista do Curso de Graduaçāo de Pedagogia - Unesc

ISSN $2526-4559$

\subsection{Cuidar e Educar no Berçário}

Conforme vimos no processo histórico da Educação Infantil, o cuidar estava somente relacionado às necessidades do corpo e ao papel assistencialista da creche. Como a Educação Infantil passou a ser considerada a primeira etapa da educação básica, surgiu a necessidade de unir o "cuidar" com atividades de caráter pedagógico. O "binômio educar e cuidar", de acordo com Kramer, tem como objetivo esclarecer essa relação entre as duas palavras, que mesmo com significados diferentes, se complementam (KRAMER, 2005).

Porém, ainda causam questionamentos, partindo de profissionais que atuam com as crianças pequenas, onde é necessário trocar fraldas, dar mamadeira, e em algumas situações dar banho. Por tratar-se de berçário, alguns profissionais acreditam que cuidar gira em torno apenas dos cuidados de higiene e alimentação e que o educar se refere as atividades pedagógicas, resultando assim numa "conotação hierárquica, [...] as professoras se encarregariam de educar (mente), e as auxiliares, de cuidar (corpo).” (KRAMER, 2005, p. 69).

O cuidar e o educar devem sempre caminhar juntos. Os documentos oficiais já abordam essa questão, como constam nas Diretrizes Curriculares Nacionais para a Educação Infantil, que, "A educação em sua integralidade, entendendo o cuidado como algo indissociável ao processo educativo." (BRASIL, 2010, p. 19), ou seja, é importante que o profissional da Educação Infantil exerça sua prática pedagógica visando o cuidar e educar das crianças.

Kramer (2005) propõe a necessidade de fazer uma reflexão sobre a especificidade da palavra cuidar. O cuidar é específico da Educação Infantil? Será que cuidamos apenas das crianças pequenas que necessitam de ajuda para realizar algumas atividades de cuidado? Refletindo acerca disso, podemos perceber que há atividades que são específicas da Educação Infantil, e outras que pertencem a outras áreas. Neste caso, "no processo de educação, em qualquer nível de ensino, cuidamos do outro.” (KRAMER, 2005, p. 63). O cuidado pode estar presente em todos os níveis de educação, o olhar do professor, sua observação, sua atenção não corresponde a faixa etária, mas ao ser humano como um todo.

As crianças têm demandas diferentes do adolescente ou do adulto, sendo assim, para Barbosa e Horn,

Saberes Pedagógicos, Criciúma, v. 3, n³, Edição Especial 2019.- Curso de Pedagogia - UNESC 
A dicotomia, muitas vezes vivida entre o cuidar e o educar deve começar a ser desmistificado. Todos os momentos podem ser pedagógicos e de cuidados no trabalho com crianças de zero a seis anos. Tudo dependerá da forma como se pensam e se procedem às ações. Ao promovê-las proporcionamos cuidados básicos, ao mesmo tempo em que atentamos para construção da autonomia, dos conceitos, das habilidades, do conhecimento físico e social. (BARBOSA, HORN, 2001, p. 70).

Além disso, "os cenários ligados ao cuidar se configuram em espaços físicos diferentes, mas profundamente articulados, pelo objetivo comum do cuidado à criança." (COSTA, 2014, p. 68). Desta forma, o ambiente precisa ter condições necessárias para atender as crianças respeitando suas especificidades, como seus desejos, seus horários de sono, de fome, entre outros.

Além do mais, Costa diz que, $(2014$, p. 88) "o educador infantil deveria valer-se da teoria, da ciência, da tecnologia, mas também de sua sensibilidade; deveria, portanto, integrar vários campos do conhecimento em sua prática profissional." Com isso, o educador entenderia que o foco do seu trabalho é a criança e compreenderia suas particularidades conseguindo assim, planejar sua prática visando o cuidar e o educar (COSTA, 2014). Nesse sentido, não há separação do corpo e da afetividade, ou seja, ao cuidar de trocar as fraldas, o professor tem a sensibilidade e o carinho de fazer isso com paciência, com cuidado, o que pode ser considerado educar.

Por fim, as rotinas na Educação Infantil contribuem para a organização do tempo tanto das professoras, quanto das crianças, portanto, trataremos a seguir sobre as rotinas do berçário.

\subsection{Planejar o espaço e o tempo no berçário}

O berçário possui necessidades específicas, pois as crianças menores demandam maiores cuidados e são ainda dependentes dos adultos. Nessa fase de desenvolvimento acontecem muitas aprendizagens, seja nas áreas cognitivas, sociais, motoras, entre outras. Planejar as ações para o berçário exige da professora um olhar atento, pois as crianças têm suas próprias demandas; não há uma hora certa para trocar fraldas e alimentar, cada criança possui seu ritmo, suas necessidades.

Saberes Pedagógicos, Criciúma, v. 3, n³, Edição Especial 2019.- Curso de Pedagogia - UNESC 
As crianças dessa faixa etária, de zero a um ano, tem suas necessidades bem definidas pois, segundo Schmitt (2013),

Dentro das possibilidades gradativas do desenvolvimento, os bebês, desde que nascem, são capazes de estabelecer relação com o outro, incluindo seus coetâneos. É necessário endossar tal afirmação pelo fato de que suas relações são atravessadas por aspectos culturais que diversificam as suas vivências e a fomentação de suas infâncias, o que rompe com a ideia única e evolutiva do bebê. Assim, a creche se apresenta como espaço social, contexto onde os sujeitos se encontram cotidianamente, se comunicam, produzem e compartilham significados e sentidos.

As crianças da faixa etária de zero a um ano necessitam do outro para realizar suas demandas físicas, especialmente. Precisam do outro para se alimentar, cuidar da higiene e aprender a se relacionar. As crianças aprendem a sorrir, a brincar, se comunicar; é a fase em que estão se construindo como sujeitos em todos os aspectos. Nesta fase, elas estão no estágio impulsivo-emocional, onde todo tipo de relação com o meio é baseada nas emoções. É nesse estágio que a criança vai desenvolver o olhar, pegar e andar (GALVÃO, 1995).

Nessa fase a criança exerce a ação sem reflexão, sempre que quiser mostrar ou dizer algo fará por meio de gestos. Não consegue imaginar e nem realizar nada sem ser por meio da representação, porque ela ainda não consegue separar de si o espaço em que está inserida (WALLON, 1995). Portanto, é por meio do movimento, dos gestos, das ações e reações que as crianças de zero a um ano se comunicam, por isso é essencial o olhar atento do professor para que consiga compreender suas demandas e construir um espaço que atenda as necessidades de todas.

Com isso, é importante que haja uma organização do espaço e do tempo, ou seja, que haja uma rotina para as crianças. Para a organização do espaço e tempo do berçário, a figura do professor é essencial, pois serão suas observações do grupo e das crianças individualmente que constituirão os projetos e as práticas pedagógicas. Assim,

Organizar o cotidiano das crianças na Escola Infantil pressupõe pensar que o estabelecimento de uma sequiência básica de atividades diárias é, antes de mais nada, o resultado da leitura que fazemos do nosso grupo de crianças, a partir, principalmente de suas necessidades. (BARBOSA, HORN, 2001, p. 67). 
Cada momento vivido no berçário é ponto de observação para o professor, seja quando as crianças estejam engatinhando no tapete, brincando com as bolas, se alimentando, descansando, quando se acalmam ou se agitam. O olhar atento do professor é que vai encaminhar os projetos. Em conjunto, é importante levar em consideração, o contexto sociocultural e a proposta pedagógica da escola (BARBOSA; HORN, 2001). Além disso, cada criança tem seu ritmo e sua forma de expressar seus desejos e suas vontades, por isso é importante que o professor leve em consideração o ritmo de cada criança para a organização do espaço e tempo da sua sala (BRASIL, 2010). Os bebês vão se adaptando às rotinas da instituição, porém vão contribuindo com suas histórias particulares.

A organização do espaço é fundamental para o desenvolvimento da criança. Como as crianças pequenas estabelecem seu contato com o meio através do corpo, é essencial que os espaços onde a criança vai explorar não sejam iguais. É importante lembrar que o ambiente é formado por diversos fatores e isso deve ser pensado no momento da organização. Além disso, "é importante educar as crianças no sentido de observar, categorizar, escolher e propor, possibilitando-lhes interações com diversos elementos" (Barbosa, Horn, 2001, p. 73). Os espaços destinados ao berçário devem ser planejados e condizer com as intencionalidades pedagógicas.

A organização do espaço é acima de tudo social e está totalmente ligada com o tempo de forma indissolúvel, esse espaço recebe grandes influências da cultura e do meio que as crianças estão inseridas. Como os bebês possuem alto grau de dependência dos adultos, para a organização do espaço é preciso entender como essas crianças interagem nesse espaço (BARBOSA; HORN, 2008). Pois "a forma como organizamos o espaço interfere significativamente nas aprendizagens infantis." (BARBOSA; HORN, 2008, p. 49). Então, o espaço precisa ser cada vez mais desafiador, para que a criança construa novas aprendizagens.

O objetivo de organizar os espaços, e relacioná-los às intenções pedagógicas, precisa desafiar os bebês a ser autônomos, a realizar tarefas sozinhos e se apropriar de novos conhecimentos. Ainda assim, todos os espaços da educação infantil são educadores como, "hall de entrada, biblioteca, banheiros [...] na medida em que, devido às suas peculiaridades, promovem o desenvolvimento das múltiplas linguagens infantis." (BARBOSA; HORN , 2008, p. 51).

Saberes Pedagógicos, Criciúma, v. 3, n³3, Edição Especial 2019.- Curso de Pedagogia - UNESC 


\section{SABERES PEDAGÓGICOS}

Revista do Curso de Graduaçāo de Pedagogia - Unesc

ISSN $2526-4559$

Por fim, o modo como os educadores organizam o espaço e o tempo revelam seus conhecimentos, demonstram a identidade da sala e, especialmente, como as demandas dos bebês são atendidas.

\section{METODOLOGIA, APRESENTAÇÃO E ANÁLISE DE DADOS}

Esta pesquisa é de abordagem qualitativa, teve como objetivo analisar as práticas pedagógicas das professoras nas turmas de berçário na Educação Infantil. A pesquisa segundo Gil (1991, p.19) "tem como objetivo proporcionar respostas aos problemas que são propostos. A pesquisa é requerida quando não se dispõe de informação suficiente para responder ao problema.”Neste sentido, procurou-se analisar as práticas pedagógicas das professoras nas turmas de berçário e que se consideram importantes planejar nessa modalidade.

O tipo de pesquisa quanto a sua natureza foi básica, pois procurou contribuir para a melhoria das práticas pedagógicas das professoras da Educação Infantil das turmas de berçário. A pesquisa teve caráter exploratório e descritivo, uma vez que foi realizada em campo, para descrever as características das práticas pedagógicas das professoras por meio de coleta de dados.

A pesquisa de campo foi realizada em uma escola particular que atende do berçário ao $5^{\circ}$ ano do Ensino Fundamental e em um CEI da rede municipal de Sombrio/SC. Para isso, construiu-se um roteiro de entrevista, com sete (7) perguntas semiestruturadas. As entrevistas foram agendadas via mensagens e de acordo com a disponibilidade de cada professora e aconteceram presencialmente. As entrevistadas aceitaram que as entrevistas fossem gravadas, sendo que se usou um dispositivo móvel e posteriormente transcritas. Os sujeitos da pesquisa foram6 professoras da Educação Infantil, onde quatro delas já atuaram nas turmas de berçário e duas estão atuando. As professoras serão identificadas como P1, P2, P3, P4, P5 e P6.

Por fim, para apresentar a coleta de dados definiram-se blocos de análise, sendo eles: As demandas dos bebês e o planejamento; O lugar do cuidar e educar no planejamento. 


\section{SABERES PEDAGÓGICOS}

Revista do Curso de Graduaçāo de Pedagogia - Unesc

ISSN $2526-4559$

\subsection{As demandas dos bebês e o planejamento}

Com o objetivo de fazer uma análise sobre as práticas pedagógicas das professoras das turmas de berçário, verificou-se como essas professoras do berçário destacam ser importante fazer o planejamento pedagógico.

Sabe-se que as rotinas no berçário, muitas vezes, ditam as regras para as dinâmicas nessa turma, logo se questionou sobre a importância da rotina nas salas de berçário para as professoras. Para as P2, P3, P4, P5 prevaleceu a ideia de que a rotina serve para organizar as atividades relacionadas ao cuidado.

Nesse sentido, a professora P5 comenta que é importante ter uma rotina no berçário para ter horário da mamadeira, trocas e descanso, e a P3 diz que "A rotina é o norte do trabalho. É importante para conseguir dar conta e por ter muitas crianças na turma.". Desse modo, percebe-se que as falas das professoras demonstram que a rotina é essencial para a dinâmica na sala do berçário, inclusive a P3 a coloca como norteadora do trabalho.

As professoras P1 e P6 entendem que a rotina é necessária no berçário, e de acordo com P1 "a rotina nos berçários deve ser flexível de acordo com o ritmo de cada criança". E, de acordo com P6 "Rotina é um roteiro que vou seguir todos os dias para não esquecer de nada. É importante no berçário para ter um bom funcionamento, uma boa organização, até para a professora botar o planejamento em prática.” Para P1 e P6, a rotina também tem grande significado, porém elas citam o planejamento e salientam a flexibilidade e as singularidades das crianças, o que de acordo com Brasil (2010) cada criança tem seu ritmo e forma de expressar seus interesses, sendo assim o professor deve respeitar o tempo de cada criança no momento de elaborar a rotina.

As professoras consideraram as rotinas no berçário importante, cada qual com seus entendimentos, portanto, fez-se necessário perguntar como elas lidam com as diferentes demandas dos bebês perante a rotina. Nesse sentido, P1, P2, P3, P4 e P5 disseram respeitar a individualidade e o tempo de cada criança. Para ilustrar essa afirmação, P1 citou como exemplo, quando uma criança está com sono e ainda não está na hora do descanso, deve respeitá-la e deixá-la dormir, e, P3 comentou que "Tem que ter cautela e saber respeitar a idade de cada um e proporcionar diferentes atividades."

Saberes Pedagógicos, Criciúma, v. 3, n³, Edição Especial 2019.- Curso de Pedagogia - UNESC 


\section{SABERES PEDAGÓGICOS}

Revista do Curso de Graduaçāo de Pedagogia - Unesc

ISSN $2526-4559$

Segundo as DCNEI (BRASIL, 2010) cada criança tem seu tempo de realizar as atividades e suas características específicas, ou seja, nenhuma criança é igual à outra, portanto, deve-se respeitar essa individualidade no momento de elaborar a rotina. Sob esta lógica, as falas das entrevistadas contemplam as Diretrizes e o RCNEI: "para que as aprendizagens infantis ocorram com sucesso é preciso que o professor considere na organização do trabalho educativo [...] a individualidade e a diversidade.” (BRASIL, 1998, p.30).

As entrevistadas compreendem que a rotina é importante para a organização e funcionamento do berçário e a maioria delas salientou que a rotina é flexível. Desse modo, suas falas condizem com o que a legislação recomenda. Sendo assim, a rotina se faz presente, porém, respeita o ritmo das crianças.

A partir destes questionamentos acerca da rotina e da forma com que as professoras lidam com as mesmas, surgiu a necessidade de perguntar às professoras sobre a relação do cuidar e educar e a forma com que elas inserem essa relação no seu planejamento.

\subsection{O lugar do cuidar e o educar no planejamento}

O cuidar e o educar tem relação direta com a rotina e o planejamento, pois ainda há professoras que dizem que o cuidar está relacionado às rotinas de higiene e cuidado pessoal e o educar está atrelado ao conhecimento, às atividades ou práticas pedagógicas. Assim, as professoras apresentaram seus entendimentos sobre cuidar e educar, com isso P1 disse que,

Cuidar e educar caminham juntos, nos berçários principalmente, essa função do cuidar é muito presente, mas, não podemos esquecer a nossa real função de educar. Sua importância está onde os educadores devem organizar o tempo para desenvolver propostas que estimulem a criança.

Além da fala de P1, P6 também expõe sua ideia sobre cuidar e educar destacando

que:

Cuidar é estar atendendo as necessidades físicas e emocionais das crianças e ao mesmo tempo educando através de propostas que desenvolvam a aprendizagem. Sendo que somente o cuidar não vai promover um desenvolvimento completo da criança, ou seja, o cuidar e educar tem que andar juntos, principalmente na Educação Infantil, que é a fase onde a criança aprende de forma lúdica e precisa mais dos cuidados de um adulto.

Saberes Pedagógicos, Criciúma, v. 3, nº3, Edição Especial 2019.- Curso de Pedagogia - UNESC 


\section{SABERES PEDAGÓGICOS}

Revista do Curso de Graduaçāo de Pedagogia - Unesc

ISSN 2526-4559

Ainda, nesse sentido, P3 afirma que "Cuidar e educar tem que caminhar juntos, pois, ao mesmo tempo em que se cuida, educa e na Educação Infantil não é só educar, pois a criança precisa se sentir segura”. Logo, as falas das professoras relacionam-se com o que diz Schimitt (2013) onde “cuidar não envolve só uma habilidade técnica, mas atenção, reflexão, contato e, levando-se em conta o componente emocional, cuidar envolve carinho, atenção ao outro. Trata-se de algo da ordem do corpo, da emoção e da mente, de modo integrado". Dessa forma, o cuidado deve estar aliado ao educar, pois não podemos exercer apenas as funções voltadas para os cuidados físicos e esquecer-se do aspecto cognitivo dos bebês, já que os mesmos estão em desenvolvimento, e o processo de aprendizagem não descarta os cuidados.

Já, quando perguntado à professora $\mathrm{P} 2$ sobre o cuidar e educar, a mesma faz o seguinte comentário: "A gente cuida da melhor maneira possível, apresentando para eles as dificuldades do dia a dia sempre com muito carinho e amor. É o principal, pois é começo deles nessa trajetória.". Em sua exposição, a professora destaca o cuidado enquanto amor e carinho e afirma que é o principal, de acordo com Costa (2014) "para uma grande parte dos profissionais na Educação Infantil, o cuidado revela-se como simples atividades que devem ser realizadas junto as crianças, geralmente visando atender demandas de ordem orgânica: vestir, trocar, higienizar, alimentar, entre outras", nesse caso, P2 vai além das necessidades físicas e destaca também a importância do afeto nessa relação cuidar e educar.

As questões relacionadas ao planejamento refletiram o início do ano letivo, momento que foram realizadas as entrevistas e muitas das crianças estavam em fase de adaptação, sendo que algumas crianças começaram a frequentar a instituição pela primeira vez. A pergunta foi: Como elaboram seus planejamentos? A professora P2 afirmou fazer seu planejamento a cada quinze dias; a P3 disse que procura fazer seu planejamento semanalmente por ter algumas semanas que não conseguia realizar seu planejamento por conta dos choros. Já, as professoras P4 e P5 disseram que fazem seus planejamentos diariamente, e a professora P6 afirmou fazer seu planejamento de forma quinzenal, baseandose no projeto do CEI.

Foi feita a seguinte questão: qual a relevância do planejamento? Cabe ressaltar que todas as seis (6) entrevistadas afirmaram trabalhar com projetos. A P1 fez o seguinte comentário, "O planejamento deve levar em conta a faixa etária da criança e o contexto social.

Saberes Pedagógicos, Criciúma, v. 3, n³, Edição Especial 2019.- Curso de Pedagogia - UNESC 
O planejamento deve buscar estimular a criança, no caminhar, no tocar. O berçário é exatamente isso, proporcionar um espaço estimulador." Nessa fala, a professora traz elementos essenciais da estruturação do projeto, que segundo Barbosa e Horn (2008) salientam que trabalhar com projetos é essencial na Educação Infantil, especialmente com os bebês, pelo fato de necessitarem de um trabalho flexível, pois estão a todo instante explorando o ambiente, expressando seus gostos e sempre exigindo novas dinâmicas.

Tendo em vista que para planejar as rotinas deve-se levar em consideração o estágio de desenvolvimento da criança, perguntou-se as professoras se no momento do planejamento elas levam em consideração os estágios de desenvolvimento de cada criança. As professoras P1, P2, P3, P4 e P6 afirmaram considerar o estágio de desenvolvimento de cada criança no momento de planejar as atividades. Para ilustrar a professora P4 aponta que "cada criança tem sua individualidade. $\mathrm{O}$ que se faz com uma criança de 5 meses, não se faz com uma de 1 ano". Semelhante a fala de P4, a P6 argumenta que "cada estágio de desenvolvimento precisa ser estimulado adequadamente, analisando qual atividade vai atingir a aprendizagem".

As professoras destacaram as especificidades das diferentes faixas etárias, inclusive salientando que há disparidade de demandas entre um bebê que não engatinha de um que começa a dar os primeiros passos. Conforme Brasil (2010) deve-se respeitar os ritmos e as especificidades de cada criança no momento de organizar a rotina e o planejamento, especialmente no berçário, onde há crianças de quatro (4) meses a um (1) ano de idade.

A maioria das entrevistadas demonstram em suas falas, que o planejamento é importante e que o cuidar e educar devem estar inseridos nos projetos, além de levar em consideração a faixa etária e o desenvolvimento individual. Desse modo, percebeu-se que suas falas foram pertinentes e coerentes com as documentações da Educação Infantil.

\section{CONCLUSÃO}

Ao desenvolver o projeto de pesquisa e refletir sobre o objeto de investigação, o berçário e sua dinâmica de planejamento chamaram atenção. Pensar sobre como deve ser o planejamento no berçário trouxe muitas questões que necessitavam de respostas. Neste 
sentido, a pesquisa possibilitou verificar como as professoras entendem a relação entre cuidar e educar e se os relacionam com o planejamento.

Percebeu-se que todas as entrevistadas consideram o planejamento no berçário importante, inclusive destacam a metodologia de projeto como sua prática. As professoras afirmaram que é necessário ser flexível e atender aos diferentes ritmos dos bebês. Desse modo, percebeu-se que as mesmas têm intencionalidades pedagógicas nas suas práticas.

As professoras compreendem os conceitos de cuidar e educar, embora, em alguns momentos, determinadas professoras destacaram o cuidar como mais importante. Porém, a maioria das entrevistadas afirmou que os dois têm que caminhar juntos, não podendo ser separados. Suas falas demonstraram que a rotina é essencial para a organização dos tempos do berçário, e algumas destacaram que a rotina é norteadora das ações o que pressupõe os cuidados com o corpo, como determinantes dessa turma.

Além disso, no que diz respeito à relação do planejamento com a organização da rotina, algumas entrevistadas entendem que rotina é para organizar o tempo, para ter horários das mamadeiras, trocas e descanso. Não reconhecem que o educar deve estar aliado ao cuidar, continuam incluindo apenas as atividades de cuidados, alegando que é difícil de aliar o educar ao cuidar por que não há tempo suficiente para realizar de forma integrada essa prática.

Percebeu-se ainda que as professoras entendem que a rotina deve respeitar os ritmos de cada criança, porém, na prática dizem que é muito difícil atender as especificidades de todas as crianças, mas procuram sempre respeitar quando uma criança está com sono e ainda não está na hora do descanso.

Por meio deste estudo foi possível perceber que as professoras mesmo apresentando certo entendimento da relação entre cuidar e educar, ainda organizam as rotinas e planejamento das turmas de berçário visando apenas o cuidar, alegando que é difícil planejar atividades para as crianças dessa faixa etária.

Por fim, o estudo permitiu analisar as intencionalidades pedagógicas das turmas de berçário da Educação Infantil, compreender a relação entre cuidar e educar, relacionar o cuidar e educar ao planejamento e verificar a importância do projeto como planejamento no berçário. Tendo em vista, a relevância da pesquisa e entendendo que o tema é inesgotável, acredita-se que futuramente possam ser pensados artigos que investiguem por meio de 


\section{SABERES PEDAGÓGICOS}

Revista do Curso de Graduaçāo de Pedagogia - Unesc

ISSN 2526-4559

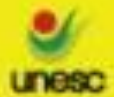

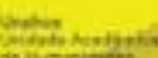

observações as dinâmicas dos berçários, para refletir sobre o que se diz e o que se faz nas turmas de berçário.

\section{REFERÊNCIAS}

ARIÉS, Philippe; FLAKSMAN, Dora. História social da criança e da família. 2 ed. Rio de Janeiro: LTC, 1981. 279 p.

BARBOSA, Silveira Carmen Maria; HORN, Souza Graça da Maria. Projetos pedagógicos na educação infantil. Porto Alegre: Artmed, 2008.

BARBOSA, Silveira Carmen Maria; HORN, Souza Graça da Maria. Organização do espaço e do Tempo na Escola Infantil. In: CRAIDY, Carmem; KAERCHER, E. Gládis (Orgs.). Educação infantil pra que te quero? Porto Alegre: Artmed, 2001. p. 68-79.

BRASIL. Ministério da Educação e do Desporto. Secretaria de Educação Fundamental. Referencial curricular nacional da educação infantil - Documento introdutório. Brasília: MEC/SEF, 1998.

BRASIL. Ministério da Educação. Secretaria de Educação Básica. Diretrizes curriculares nacionais para a educação infantil. Brasília: MEC/SEB, 2010.

BRASIL, Lei de Diretrizes e Base para Educação Nacional. Lei n ${ }^{\circ}$ 9.394/96, de 20 de dezembro de 1996.

COSTA, Fátima Neves do Amaral. O cuidar e o educar na educação infantil. In: AGOTTI, Maristela. (Org.) Educação infantil: para que, para quem e por quê. 4 ed. Campinas, SP: Editora Alínea, 2014. p.63-90

FREITAS, Cezar Marcos de. (Org.) História social da infância no Brasil. São Paulo: Cortez, 1999. p. 93.

GIL, Antonio Carlos. Como elaborar projetos de pesquisa. São Paulo: Atlas, 1991. Paulo: Atlas, 1991.

HERNÁNDEZ, Fernando. A organização do currículo por projetos de trabalho. Porto Alegre: Artes Médicas, 1998.

HERNÁNDEZ, Fernando. Transgressão e mudança na educação: os projetos de trabalho. Porto Alegre: ArtMed, 1998.

OLIVEIRA, Zilma Ramos de. Educação Infantil: fundamentos e métodos. São Paulo: Cortez, 2002.

Saberes Pedagógicos, Criciúma, v. 3, n³, Edição Especial 2019.- Curso de Pedagogia - UNESC 
RIZZINI, Irene. O século perdido: raízes históricas das políticas públicas para a infância no Brasil. Rio de Janeiro: Amais, 1997.

SCHMITT, V. Rosinete. O encontro com bebês e entre bebês: Uma análise do entrelaçamento das relações. In: ROCHA, C. A. Eloisa; KRAMER, Sonia. (Org.). Educação infantil: enfoques em diálogo. 3. ed. Campinas, SP: Papirus, 2013. p.17-35.

SILVA, Moraes Virginia Carmem da; FRANCISCHINI, Rosângela. O surgimento da educação infantil na história das políticas públicas para a criança no Brasil.dez. 2011. p. 257-276.

KRAMER, Sonia. Profissionais de educação infantil: gestão e formação. São Paulo: Ática, 2005.

GALVÃO, Izabel. Henri Wallon: uma concepção dialética do desenvolvimento infantil. Petrópolis, RJ: Vozes, 1995.

WALLON, Henri. A evolução psicológica da criança. Lisboa: Edições 70, 1995.

Recebido: 03/05/2019
Publicado: 20/09/2019 